\title{
Simulation Parameter Selection and Steady Seepage Analysis of Binary Structure Slope
}

\author{
Xuhe Gao ${ }^{1, * \mathbb{D}}$, Baocheng Cheng ${ }^{2, *}$, Weiping Tian ${ }^{1}$, Zhipei Zhang ${ }^{3}$, Jiachun $\mathrm{Li}^{1}$ and \\ Hongliang Qi ${ }^{1}$ \\ 1 Key Laboratory of Highway Engineering in Special Region, Ministry of Education, Chang'an University, \\ Xi'an 710064, China; fz02@gl.chd.edu.cn (W.T.); zhs@chd.edu.cn (J.L.); qihongl@chd.edu.cn (H.Q.) \\ 2 Henan Non-Ferrous Metals Geological Exploration Institute, Zhengzhou 450052, China \\ 3 College of Geology and Environment, Xi'an University of Science and Technology, Xi'an 710054, China; \\ zhipeizhangt@126.com \\ * Correspondence: 2017021008@chd.edu.cn (X.G.); yousebaocheng@126.com (B.C.)
}

Received: 11 August 2020; Accepted: 29 September 2020; Published: 1 October 2020

check for

\begin{abstract}
The selection of calculation parameters for slope excavation support design and the analysis of seepage stability is a significant challenge. This difficulty also hinders the development of slope support engineering. This study examined the right binary structure slope engineering of the $\mathrm{K} 5+220-\mathrm{K} 5+770$ section of the TJ1A mark of the Jiangkou-Weng'an Highway in Guizhou province. In this study, we propose and use the deep displacement monitoring data and $p$ value test method to check the simulation parameters. Furthermore, the superposition calculation method for steady-state seepage analysis of slope geotechnical structure is proposed. A comparative analysis of the displacement, strain, stress, and safety factor of the slope after the application of pore water pressure was carried out for three slope conditions. The analysis showed that steady-state seepage has a significant effect on the displacement of the slope during the completion of excavation. As a result, a continuous distribution of strain arises on the slope along the interface between the potential sliding surface and the rock-soil layer, and then forms a continuous sliding zone. Additionally, steady-state seepage has a significant effect on the position of the displacement distribution during the initial support of the slope, leading to a significant increase in the extreme value of the shear outlet displacement of the potential slip surface of the slope and in the extreme value of equivalent strain. Finally, steady-state seepage reduces the displacement and equivalent strain upon construction of the secondary slope support. The steady-state seepage has a limited effect on the stress concentration, but reduces the safety factor calculated using the strength reduction method, in all three stages of slope excavation and support. This study enriches the analysis methods for determining the stability of a dual-structure slope during the rainy season, and provides new ideas for the safety and control of slope support projects.
\end{abstract}

Keywords: slope support; superposition calculation; numerical simulation; steady-state seepage; binary structure; pore water pressure

\section{Introduction}

Slopes can be classified into three major categories, namely soil slopes, rock slopes, and rock-soil mixed slopes, based on their composite materials. In rock-soil mixed slopes, the lower part of the slope is a rock layer, whereas the upper part is a soil layer. These slopes are also known as binary structure slopes. Binary structure slopes can be further divided into soil binary structure slopes, which are soil slopes with large differences in mechanical properties between two adjacent soil layers, rock-soil binary structure slopes, where the upper layer of soil is the lower layer of the Quaternary cladding 
layer, and rock binary structure slopes. As there are many mountains in southwestern China, buildings and infrastructure are frequently built in the mountains. The binary structure slope is a common structural form in this setting as the mountain surface is overlaid by a loosely accumulated soil layer and the lower layer is hard bedrock. The structural plane is the interface between the soil and rock layers. Therefore, it is important to conduct a qualitative analysis of the factors that affect slope stability and mechanisms of slope instability, and to quantitatively evaluate slope protection methods [1,2].

Seepage is the movement of water into the voids of the soil, and it has a significant effect on slope instability. Research into seepage has been conducted for nearly 200 years. As early as 1856, French engineer Henri Darcy established a linear law of permeability through experiments. This was the first study investigating the theory of seepage, and it is one of the most important foundations for the study of seepage action today [3]. Although soil is a three-phase medium material, the soil body can generally be simplified into a two-phase medium composed of the soil skeleton and water due to the small specific gravity of air. Darcy's law notes the linear relationship between the penetration velocity and the pressure gradient. That is to say, the straight line formed by the two parameters should pass through the origin of the coordinate axis and deviation from this line is called "non-Darcy seepage".

The real application of seepage theory in the field of geotechnical engineering began with $\mathrm{K}$. Terzaghi in 1924. When studying the settlement of soil, Terzaghi proposed the principle of effective stress and considered that the water in the soil conforms to Darcy's law of seepage, unveiling this classic topic in the study of soil mechanics [4,5]. Following this, Rendulic (1935) extended Terzaghi's one-dimensional consolidation theory to two and three dimensions. Furthermore, Biot (1956) derived the fluid-solid coupling equation of the soil from Terzaghi's one-dimensional soil consolidation theory. This equation reflects the characteristics of the interaction between the pore pressure dissipation and the soil skeleton, which lays the foundation for the study of the effect of groundwater seepage on the soil and provides the theoretical basis for earth pressure calculations and slope stability analysis [6].

Numerical simulation provides an important means to solve the equations for slope instability when considering seepage and allows the development of different seepage calculation models. For example, the earth-rock dam stability calculation involved the concept of seepage. Mao studied the seepage calculation model and successfully applied it to the anti-sliding stability calculations for the area around the dam [7]. Liu outlined the characteristics of seepage stability and control of soils and focused on describing the seepage resistance characteristics of both non-cohesive and cohesive soils. Liu also established the seepage control calculation equation for an earth-rock dam and developed the numerical method of seepage calculation [8].

In other studies involving numerical simulation, Lam and Fredlund discussed saturated-unsaturated soil, proposed a method for calculating water flow with a water head gradient, determined the unsaturated seepage control equation, and analyzed the seepage of complex groundwater flow by the finite element method [9]. Shao used porous media mechanics to establish the equilibrium differential equation for soil mechanics, from which the stress equation of the soil skeleton was derived and extended to the unified equation of saturated and unsaturated soils. This stress equation of the soil skeleton also allowed the verification of the seepage calculation by the finite element limit equilibrium method [10].

Early studies in this area have been built upon in more recent years. Mao proposed the finite element method of arc sliding-replacing the water pressure around the vertical soil strip with the penetration force of the triangular element, taking into account the influence of the direction and moment of the seepage-and calculated the relationship between seepage and the landslide. Mao also promoted the limited application of this finite element calculation in slope seepage analysis [11]. Gao et al. used Biot's consolidation theory to establish the differential equations for the two-field coupled model of a stress field and a seepage field and determined the solution of the two-field coupled finite element equations. The calculation of stability was also numerically simulated [12]. Zhang proposed a polynomial constrained optimization model of a soil-water characteristic curve, compiled a saturated-unsaturated soil seepage calculation program, and took the Zhaoshuling landslide as an example to analyze the landslide seepage field and water level decline under different working 
conditions [13]. Zhang (2006) calculated the stability of the slope caused by water level fluctuation in unsaturated-saturated seepage through numerical simulation [14]. Wang used the elastic modulus reduction method for a variable modulus to numerically simulate the deformation of an embankment caused by seepage due to different rainfalls and compared the results with those obtained using the Bishop limit equilibrium method. The stability of the embankment slope and the changing law of the arc of the sliding surface were also investigated [15]. Finally, Z. Zhang and Gao established a finite element model of a loess landslide based on the strength reduction method to obtain the potential sliding surface position and the overall stability coefficient of the slope as well as the cut position of the slope and the relatively weak zone [16].

In summary, over the past few decades, there has been significant research into slope stability under seepage conditions. However, most studies assume that the slope body is composed of homogeneous soil, whereas the actual geological conditions of the slope are quite complex and mostly heterogeneous. At present, there are relatively few studies on heterogeneous slopes, and the research on determining geomechanical parameters based on random machine methods has strong reference significance [17-19]. In addition, the research process in these existing studies is mostly a single-factor analysis of indoor experiments, numerical simulation of given parameters or qualitative analysis of theoretical discussion. In any case, these studies typically lack parameter verification and process analysis. Based on previous research results, this paper examined the right-side slope of the $K 5+220$ to $K 5+770$ section of the TJ1A mark of the Jiangkou-Weng'an highway in Guizhou Province and used the strength reduction method to evaluate the dual-structure slope. During the analysis of the support process, pore water pressure was superimposed by finite element calculation and the effects of applied pore water pressure on the deformation characteristics of the slope were assessed. A comparative analysis of the displacement, strain, stress, and safety factor of the slope at three stages was performed after the application of pore water pressure. These results provide not only design and construction insight for slope management projects, but also enrich the theory of analysis of the stability and reinforcement of dual-structure slopes under seepage conditions.

\section{Materials and Methods}

\subsection{Study Area}

During the excavation of the right slope of section $K 5+220$ to $K 5+770$, tension cracks formed on the ground surface three times. Accordingly, different degrees of slippage occurred, and construction safety was seriously affected. The first instance occurred on 3 April 2014, when ground cracks formed in section K5 + 680 to K5 + 770, causing slope slip. The second instance occurred on 1 June 2014, in the $\mathrm{K} 5+540$ to $\mathrm{K} 5+680$ section of the right slope between 30 and $50 \mathrm{~m}$ north of the west side. Due to the lack of timely treatment and continuous rainfall, the first landslide continued to develop, inducing a second traction slip. The third occurrence was on 28 September 2014, when ground surface subsidence occurred between $\mathrm{K} 5+385$ and $\mathrm{K} 5+500$.

The first support was designed for the left and right sides of the $\mathrm{K} 5+327$ to $\mathrm{K} 5+520$ section. The grade of the first slope was 1:0.75 and it had a height of $8 \mathrm{~m}$ and a window-type retaining wall for protection. The second slope had a grade of 1:0.75, a slope height of $8 \mathrm{~m}$, and grass planted in a prestressed anchor cable frame for protection. The anchor cable was $20 \mathrm{~m}$ and the anchor was $10-\mathrm{m}$ long. The third slope had a grade of 1:1, a slope height of $8 \mathrm{~m}$, and grass planted in a prestressed anchor cable frame for protection. The anchor cable was $20 \mathrm{~m}$ long and the anchor was $10 \mathrm{~m}$ long. Finally, the fourth slope had a grade of 1:1 and reached the top of the slope. The fourth slope was protected by a grass block and stone grid.

Anti-sliding piles were added at the third-level platform for additional reinforcement. The crosssectional dimensions of the anti-sliding piles were $3 \times 2.4 \mathrm{~m}$, the distance between the piles was $5.0 \mathrm{~m}$, and the length of the piles was $30 \mathrm{~m}$. Three levels of anchor cables were added for slopes 2 and 3 . The slope was reinforced every $3 \mathrm{~m}$ and the anchor cable was a 4 Фs 15.24 scattered-type cable with a 
downward tilt of $20^{\circ}$, and a drilling hole diameter of $130 \mathrm{~mm}$. The total length of the anchor cable was $20 \mathrm{~m}$, the anchor section was $10 \mathrm{~m}$ long, and the anchor cable prestress was $500 \mathrm{kN}$.

On 28 September 2014, cracking occurred on the right slope of the K5 + 385 to K5 + 500 section. The cracks were intermittently continuous arcs, ranging from a few to a dozen meters long, $1-3 \mathrm{~cm}$ wide and 0.4-2.0 m deep. The second stage of reinforcement was thus designed and constructed between October 2015 and December 2016. The construction of the anti-sliding piles for the three-stage platform in section $\mathrm{K} 5+336$ to $\mathrm{K} 5+500$ was completed. The cross-section of the anti-sliding piles was $3 \mathrm{~m} \times 2.4 \mathrm{~m}$ and the pile spacing was $5.0 \mathrm{~m}$. An additional anchor beam was added to the top of the anti-sliding pile, using a $6 \Phi$ s 15.24 anchor cable tilted $28^{\circ}$ with a hole diameter of $130 \mathrm{~mm}$. The anti-sliding piles were numbered Z11 to Z17, the length of the anchor cable was $33 \mathrm{~m}$, the anchoring section was $11 \mathrm{~m}$ long, and $750 \mathrm{kN}$ of prestress was applied. A row of anchor cable anti-sliding piles was also added to the secondary platform of the slope, and the top of the pile was connected by beams. These anti-slide piles were 33 to $34 \mathrm{~m}$ long. The pile top anchor cable was of the 6 Фs 15.24 dispersion type, angled $20^{\circ}$ downhill with a drilling hole diameter of $130 \mathrm{~mm}$, and it had an anchoring section length of $12 \mathrm{~m}$ and $750 \mathrm{kN}$ of prestress. The tops of piles Z47 and Z48 were not anchored by cable. The first grade used a window hole-type retaining wall, and the fourth grade used rhombic grid planting grass to protect the slope.

A row of drainage holes was arranged on the first grade of the $\mathrm{K} 5+370$ to $\mathrm{K} 5+420$ section. The water outlet was $4 \mathrm{~m}$ higher than the crushing platform and the holes were spaced over a horizontal distance of $5 \mathrm{~m}$. A second row of drainage holes was arranged on the second grade. The water outlet was $1.5 \mathrm{~m}$ higher than the platform and the holes were spread across a horizontal distance of $5 \mathrm{~m}$. Construction on this slope section avoided the drainage hole leading from the anti-slide pile body. The drainage hole water inlet was $1 \mathrm{~m}$ deep in the sliding zone and tilted by $6^{\circ}$. The diameter of the drainage hole was $110 \mathrm{~mm}$ and the diameter of the drainage pipe, which was fabricated with PVC plastic, was $100 \mathrm{~mm}$. The spacing and depth of the drainage holes could be adjusted slightly according to the actual groundwater distribution and the positions of the anti-slide piles after slope excavation.

The climate of the region is characterized by four distinct seasons and abundant rainfall, including a wet and hot season and a dry and hot season. The average annual rainfall is $1369.6 \mathrm{~mm}$ and the precipitation is largely concentrated between May and October. A rain source "V" shaped valley developed in this section. The surface water in the landslide area is mainly rain-source ditch and stream water formed by surface runoff water from atmospheric precipitation. There is a scouring effect on the slope during the rainy season due to this surface water. According to the lithology and the hydrodynamic characteristics, the groundwater in this line section is divided into loose accumulation pore water and bedrock fissure water.

\subsection{Construction Monitoring}

\section{Monitoring Point Layout}

There are five deep displacement monitoring points in this landslide section (Table 1). The layout of the monitoring points for deep slope displacement is shown in Figure 1 and a cross section of the landslide section is shown in Figure 2. Slope slip surface is an interface formed between the landslide body and the immovable body (parent body) when the landslide body moves. According to the preliminary investigation and monitoring data, the potential slip surface of the slope is obtained.

Table 1. Deep displacement monitoring point details.

\begin{tabular}{cccc}
\hline Monitoring Point Number & Laying Depth of Measuring Tube (m) & Installation Date & Notes \\
\hline 1AJC08 & 19.5 & 2015.01 .11 & damage \\
1AJC09 & 24.0 & 2015.01 .07 & - \\
1AJC10 & 18.5 & 2015.01 .13 & - \\
1AJC11 & 21.5 & 2015.01 .04 & - \\
1AJC12 & 18.5 & 2015.01 .02 & - \\
\hline
\end{tabular}




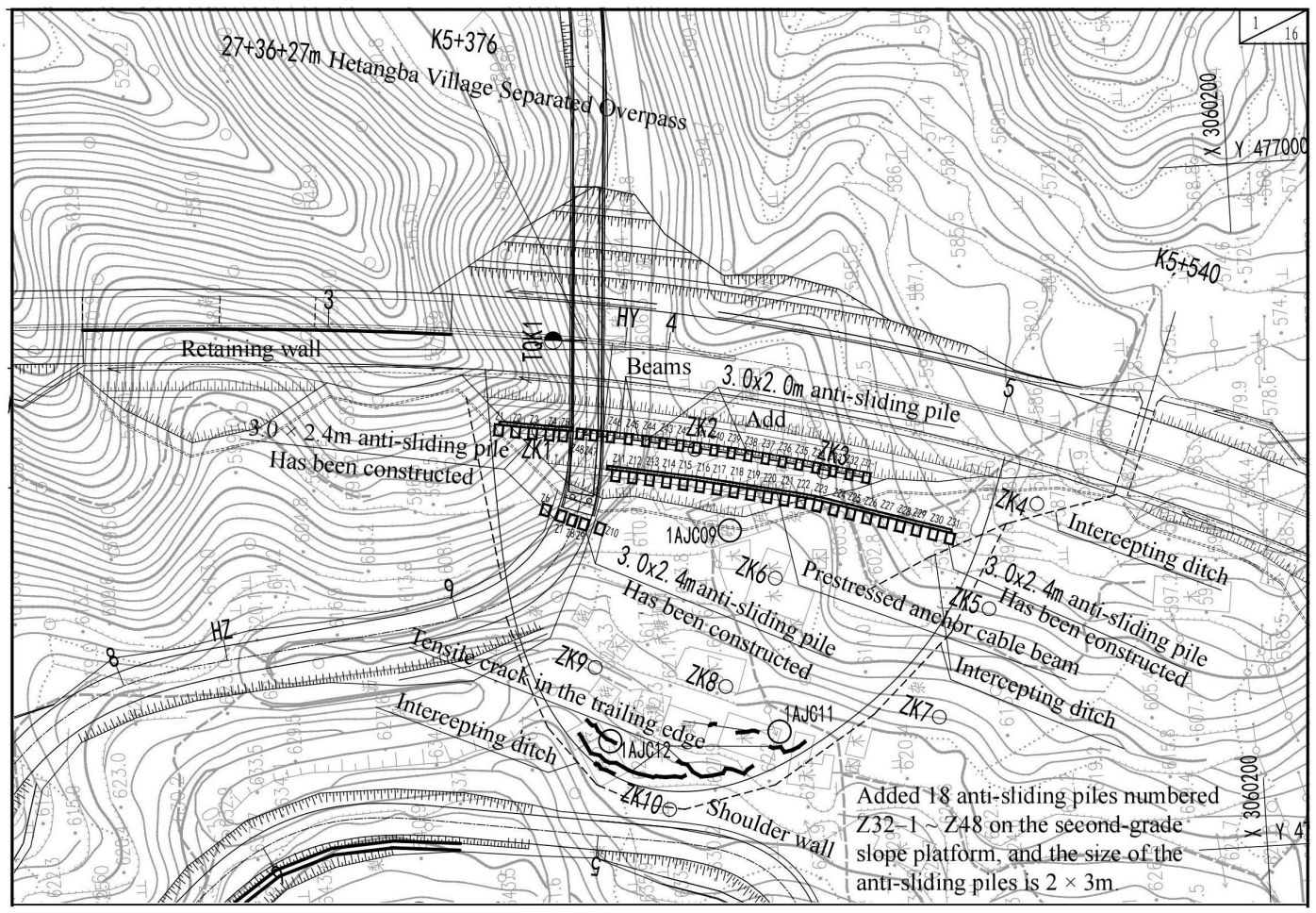

Figure 1. Schematic of deep hole displacement monitoring locations.

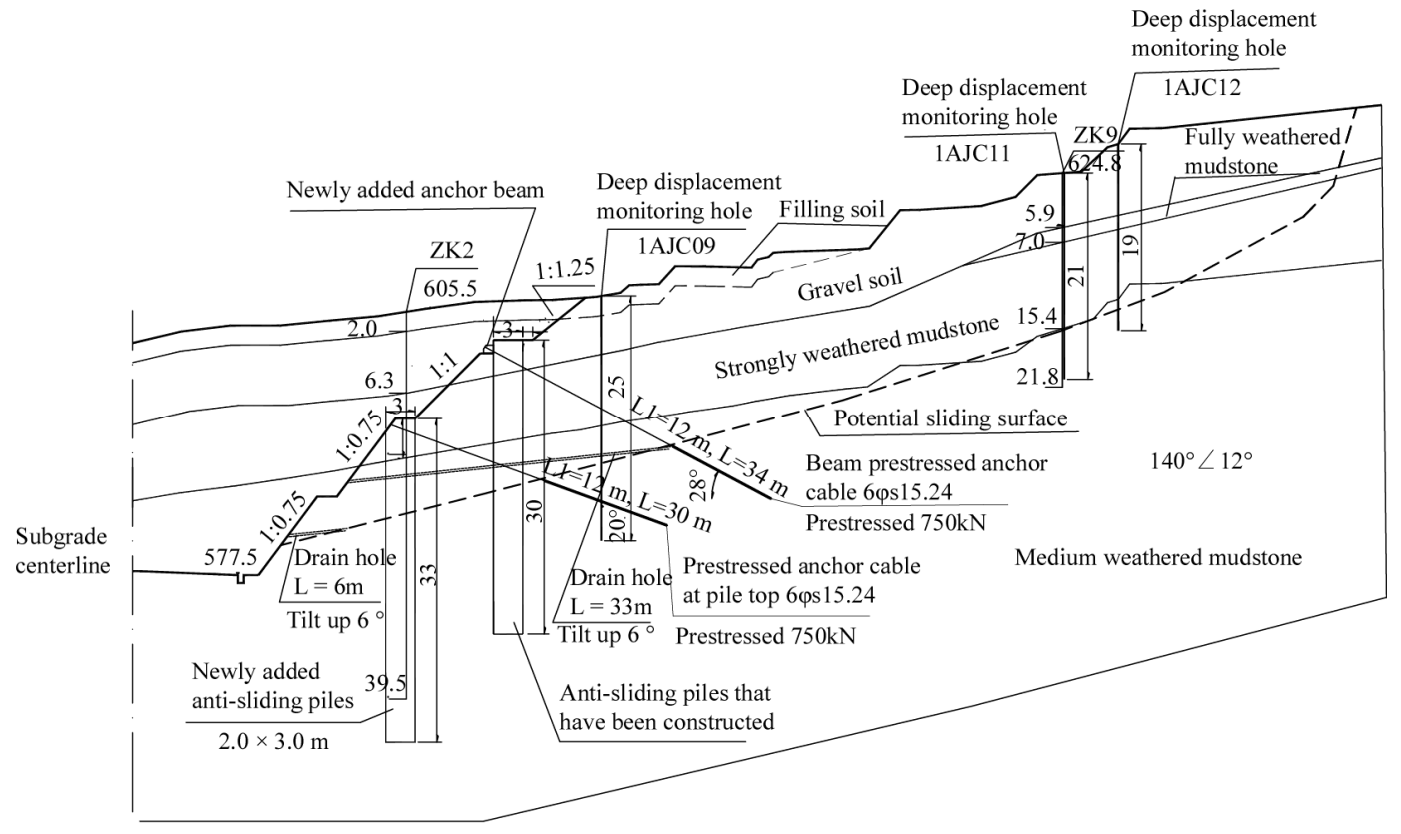

Figure 2. Cross-sectional view of the slope at $\mathrm{K} 5+420$.

\subsection{Strength Reduction Theory}

The safety factor of slope stability is defined by the strength reduction method as the degree to which the shear strength of the rock and soil is reduced when the slope just reaches the critical failure state. Thus, the safety factor is the ratio of the actual rock and soil shear strength to the reduced shear strength at failure. The main points of the strength reduction method are Equations (1) and (2), which are used to adjust the strength indices $c$ and $\varphi$ of the rock and soil. Based on these formulas, numerical analysis of the slope stability was performed, and the shear strength reduction factor was continuously increased. The calculation was repeated until the slope reached the critical failure state, 
and the strength reduction factor at this point was taken as the safety factor Fs. The formulas are as follows:

$$
\begin{gathered}
c_{F}=c / F_{\text {trial }} \\
\varphi_{F}=\tan ^{-1}\left(\tan \varphi / F_{\text {trial }}\right)
\end{gathered}
$$

where $c$ is the cohesive force, $\varphi$ is the friction angle, $c_{F}$ is the reduced cohesive force, $\varphi_{F}$ is the reduced friction angle, and $F_{\text {trial }}$ is the strength reduction factor.

\subsection{Basic Law of Seepage-Darcy's Law}

Darcy concluded through experiments that the law describing the linear relationship between the seepage velocity of water in saturated soil and the hydraulic slope is as follows [20]:

$$
Q=k A i=-k A \frac{d h}{d s}
$$

where $Q$ is the seepage flow, $A$ is the cross-sectional area of seepage flow, $i$ is the loss rate along the path $s$ (i.e., the drop in penetration ratio), and $h$ denotes height difference. It can be seen from hydraulics that the seepage flow $Q$ through a certain section is equal to the product of the velocity $v$ and the cross-section $A$, i.e., $Q=A v$. Therefore, Darcy's law can also be expressed in another form: $v=k i$, where $v$ represents the seepage velocity. Finally, Equation (3) shows that the seepage velocity is linearly related to the permeability ratio drop; thus, this equation is also referred to as the linear seepage law.

\subsection{Model Design}

\subsubsection{Simulation Assumptions and Regions}

MiMidas/GTS software was selected for modeling. By analyzing the geological conditions of the slope, the actual conditions of excavation, support, and the environment in which the slope is located, the following assumptions were made to simplify the numerical analysis.

(1) Rock and soil form an ideal elastoplastic body, which obeys the Mohr-Coulomb strength criterion.

(2) The actual seepage of the slope changes all the time, in order to avoid the calculation result misleading the influence of seepage on the stability of the slope. Therefore, the impact of groundwater and seepage on the entire project is simplified to the most unfavorable steady-state seepage.

(3) Each structural unit in the pile-anchor supporting structure is completely elastic. The supporting pile obeys an elastic constitutive model and the anchor cable behaves as an implanted truss unit.

According to the $\mathrm{K} 5+420$ cross-sectional diagram (Figure 2), combined with the requirements of the simulation calculations, the default model size along the slope was $1 \mathrm{~m}$, with a total width of $150 \mathrm{~m}$ and a height of $80 \mathrm{~m}$. The water head at the boundary node on the right was $80 \mathrm{~m}$ and on the left was $30 \mathrm{~m}$. The head of the slope drainage node was at 0 and was a pressure head. The steady-state seepage calculation conditions were designed to obtain pore water pressure, which was then exert to the three working conditions of slope excavation, primary support, and secondary support construction in order to obtain the safety factor based on the strength reduction method.

Anti-sliding piles were added at the third-level platform. The cross-sectional dimensions of the anti-sliding piles were $3 \mathrm{~m} \times 1 \mathrm{~m}$, and the length of the piles was $30 \mathrm{~m}$. Three levels of anchor cables were added for grades 2 and 3 . The slope was reinforced every $3 \mathrm{~m}$ by prestressed anchor cable with a downward tilt of $20^{\circ}$. The total length of anchor cable was $20 \mathrm{~m}$, the anchor section was $10 \mathrm{~m}$ long, and the anchor cable prestress was $500 \mathrm{kN}$. In the model of the second support construction stage, an anchor cable beam was added to the top of the anti-sliding pile on the third-level platform. The anchor cable had a downward tilt of $28^{\circ}$, a length of $33 \mathrm{~m}$, an anchor section of $11 \mathrm{~m}$, and a prestress of $750 \mathrm{kN}$. The anti-sliding pile had a cross-section of $3 \mathrm{~m} \times 1 \mathrm{~m}$ and a length of $33 \mathrm{~m}$. The anchor cable at the top 
of the pile was angled downward by $20^{\circ}$, the anchor cable was $33 \mathrm{~m}$ long, the anchor was $12 \mathrm{~m}$ long, and the anchor cable was prestressed at $750 \mathrm{kN}$.

Drainage holes were arranged on the surface of the first slope, with the water outlet located $4 \mathrm{~m}$ higher than the platform. Drainage holes were also arranged on the surface of the second slope, with the water outlet located $1.5 \mathrm{~m}$ higher than the platform. The water inlet of the drainage hole penetrated $1 \mathrm{~m}$ into the sliding zone and tilted upwards by $6^{\circ}$. The strata were divided into sliding layers, gravelly soil (accumulation), strongly weathered mudstone and moderately weathered mudstone based on survey and design data. The specific layout of the geometric design model is shown in Figure 3. The layer thickness of Fully weathered mudstone is too small, and there is a phenomenon of "pink-out" in the study area. The existence of thin layers is not a controlling factor for the overall stability of the slope under seepage conditions, so it is simplified in the modeling design.

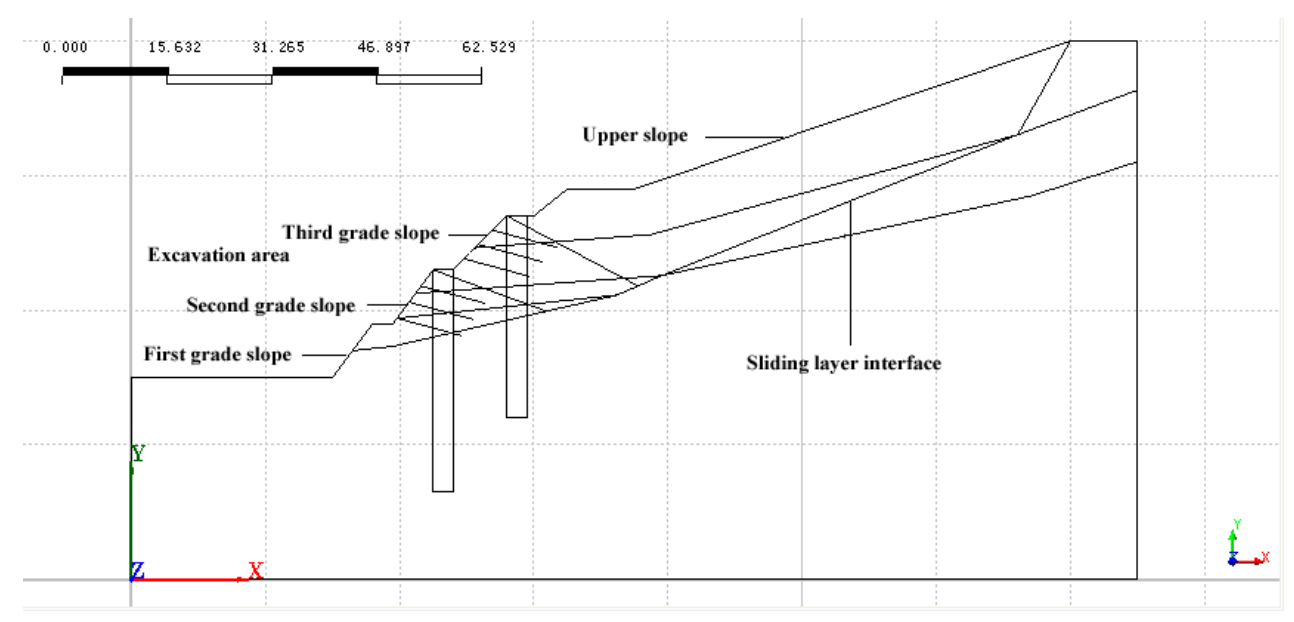

Figure 3. Geometric schematic of the K5 + 420 slope section used for modelling.

\subsubsection{Model Boundary Conditions}

The boundary conditions of the model were as follows:

(1) The $X$-axis direction of the left and right boundaries of the model is the constraint boundary. Thus, $\mathrm{u}=0$, where $\mathrm{u}$ is the displacement in the $\mathrm{X}$ direction, $\mathrm{v}$ is the displacement in the $\mathrm{Y}$ direction, and $\mathrm{w}$ is the displacement in the $\mathrm{Z}$ direction.

(2) The Z-axis direction of the front and back boundaries of the model is the constraint boundary. Thus, $\mathrm{w}=0$.

(3) The upper boundary of the model is set as a free boundary and no constraint is given.

The Mohr-Coulomb elastoplastic strength criterion was used in the calculation. The initial stress is predominantly the stress from the self-weight of the geological formation. The model grid division follows the applicability principle, that is, the rock and soil body uses a quadrilateral and triangular plane element grid, the anti-slide pile uses a linear beam element grid, and the prestressed anchor cable anchor section uses a linear truss element grid. Grid densification is performed on the excavation slope, around the anti-slide pile and the interface position of the rock-soil layer. Based on the above assumptions and considerations, a model with a length, width, and height of $150 \times 1 \times 80 \mathrm{~m}$, respectively, was established. The model had a total of 11,343 units and 22,841 nodes, as shown in Figure 4 . The study selects the right side slope of the $\mathrm{K} 5+220-\mathrm{K} 5+770$ section of Jiangkou-Weng'an Expressway as a case, so the subgrade center line is used as the boundary line during modeling, that is, the $\mathrm{X}$ direction $(\mathrm{u}=0)$ constraint is imposed on the subgrade boundary line. 


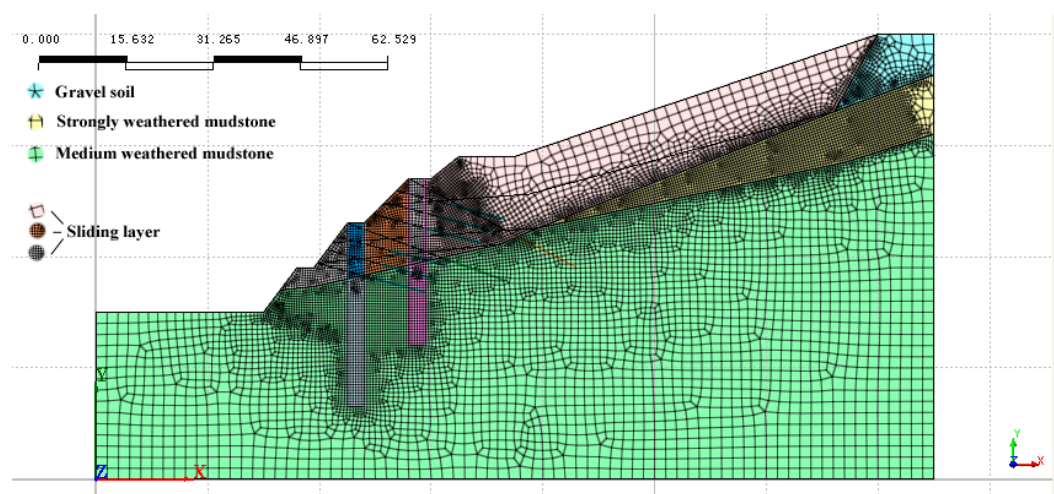

Figure 4. Mesh model diagram of the K5 + 420 slope section.

\subsubsection{Process Analysis}

Slope management projects involve both the state of the slope and the process of analysis and design. While slope management projects rarely have engineering accidents at the time of final completion or operation, many have problems during construction. To address this challenge, the steady-state seepage superposition calculation and slope supporting process analysis method are proposed. This simulation was based on the steady-state seepage calculation and the analysis of three operating conditions: slope excavation, first support construction and second support construction. Specifically, an overview of the process for our analysis is shown in Figure 5.

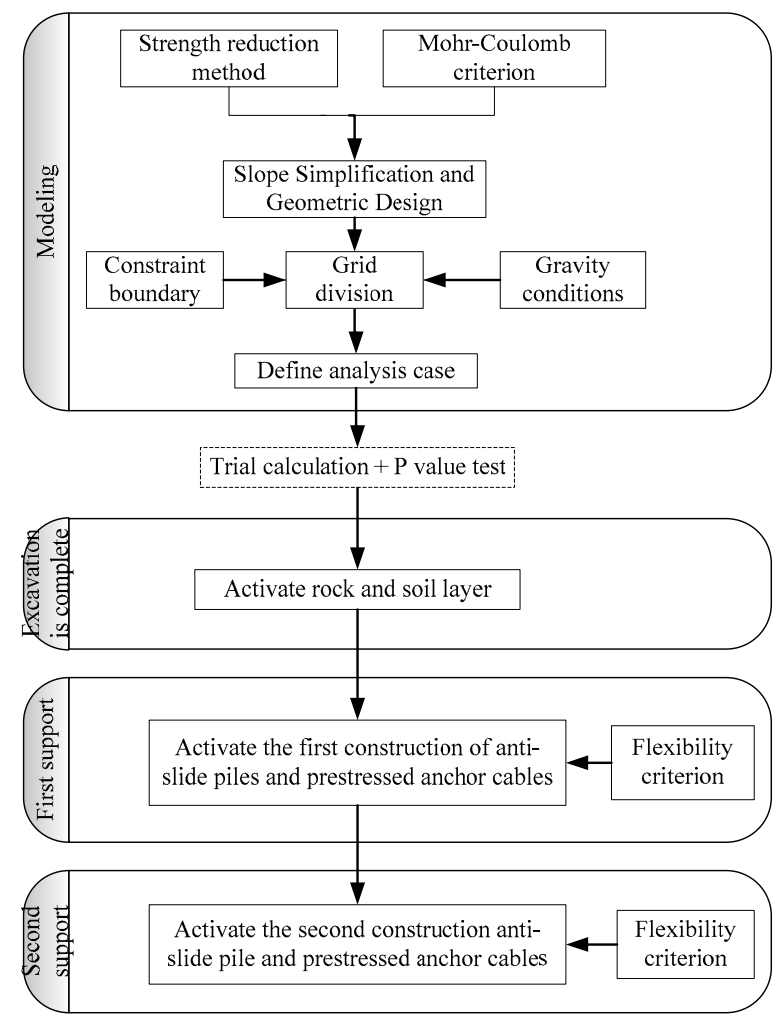

(a)

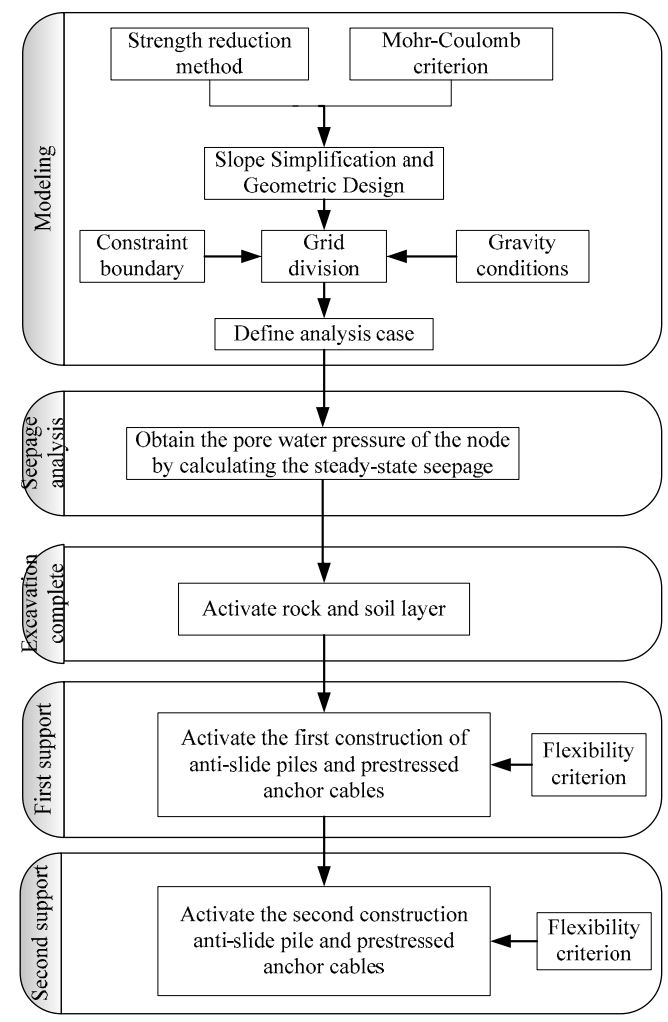

(b)

Figure 5. Modeling and calculation process flowchart. (a) Not consider seepage (b) Consider seepage.

\subsection{4. $p$ Value Test and Parameter Verification}

$p$ Value in hypothesis testing: Hypothesis testing is an important content in inferential statistics. The $p$ value is a basis for the decision making in hypothesis testing. Specifically, the $p$ value is the 
probability, reflecting the probability of an event occurring. Statistics According to the $p$ value obtained by the significance test method, generally $p<0.01$ is considered as a significant statistical difference. Its meaning is that the probability that the difference between samples is caused by sampling error is less than 0.01 .

This study proposes and uses deep displacement monitoring data and $p$-value inspection methods to check simulation parameters. As we all know, the choice of physical and mechanical parameters must be as reasonable as possible. However, there are many potential uncertain factors (including simplifying soil and rock to ideal homogeneous materials, data collection, processing, and conversion, etc.). Therefore, when the parameter selection basis is not convincing, the data obtained through monitoring is used to check the initial simulation trial calculation results. When the deviation between the result obtained by the simulation trial calculation and the monitoring value is within a certain range $(p>0.01)$, it is considered that the physical and mechanical parameters selected by the calculation model are reasonable. After that, simulation calculations are performed for other working conditions.

\section{Results}

\subsection{Deep Displacement Monitoring}

The deep displacement monitoring curves are shown in Figures 6 and 7; it can be seen that monitoring points \#9 (1AJC09) and \#12 (IAJC12) have obvious intermediate displacements. At monitoring point \#9 (1AJC09), the sliding surface was located 13.0-14.0 m deep. As of 29 August 2015 (prior to the second support construction), the cumulative maximum displacement of the sliding surface was $9.85 \mathrm{~cm}$. The maximum cumulative displacement at monitoring point \#9 over the entire monitoring period (13 January 2015 to the end of second support construction) was $12.6 \mathrm{~cm}$. At monitoring point \#12 (1AJC12), the depth of the sliding surface was 6.0-8.0 m. As of 29 August 2015, the maximum cumulative displacement at the sliding surface was $10.9 \mathrm{~cm}$, and the maximum cumulative displacement over the entire monitoring period was $15.6 \mathrm{~cm}$.

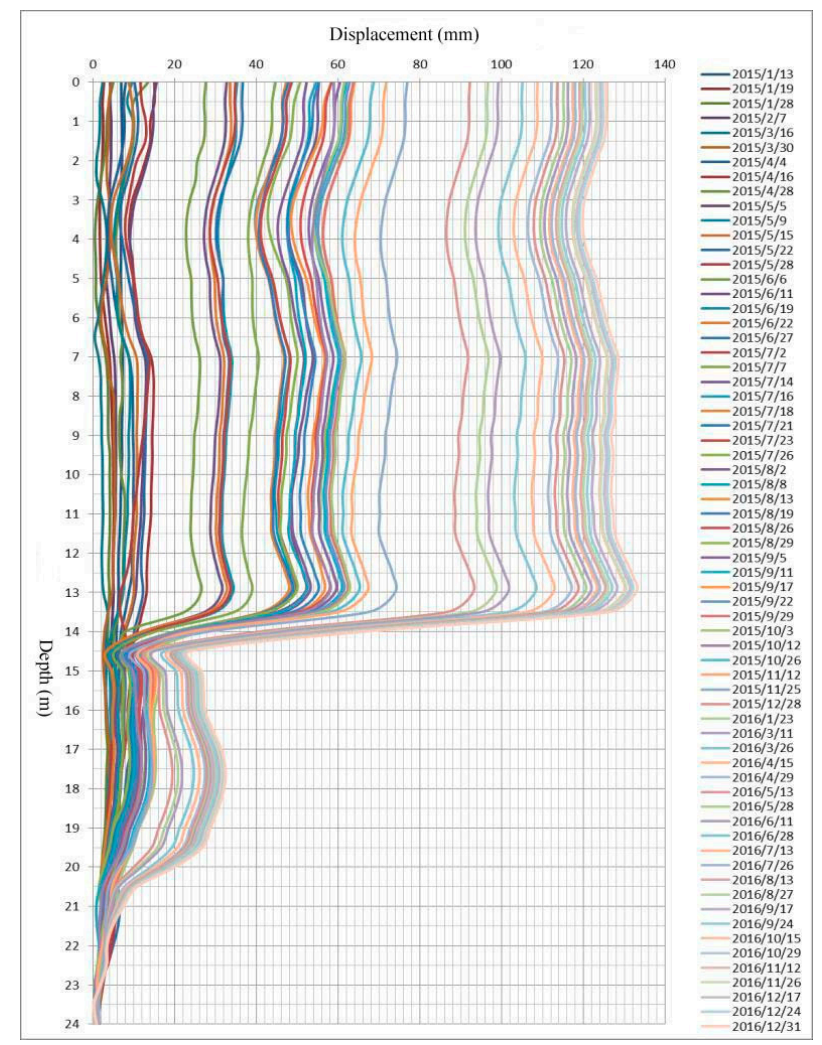

Figure 6. Monitoring Point \#9 (1AJC09) cumulative displacement curves. 


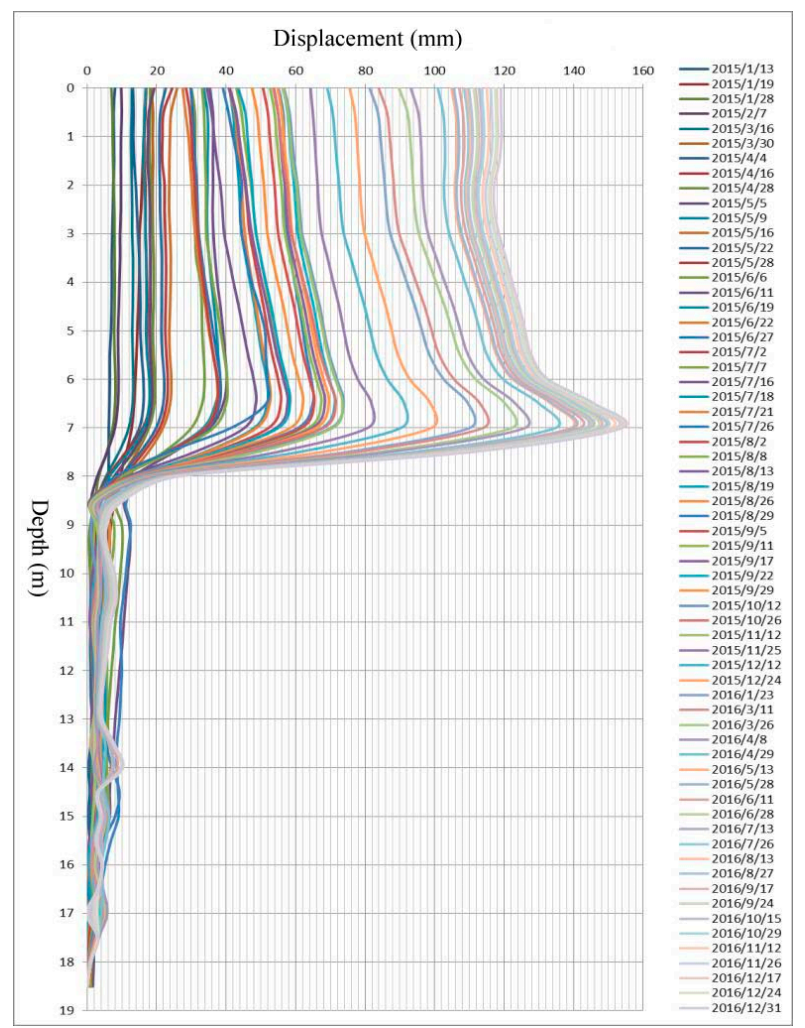

Figure 7. Monitoring Point \#12 (1AJC12) cumulative displacement curves.

\subsection{Model Validation}

From Figure 8, the maximum horizontal displacement of the formation after the first support is $0.102191 \mathrm{~m}$. The data before the second support (29 August 2015) of No. 9 and No. 12 deep displacement monitoring holes located on section $\mathrm{K} 5+420$ were selected for inspection and analysis.

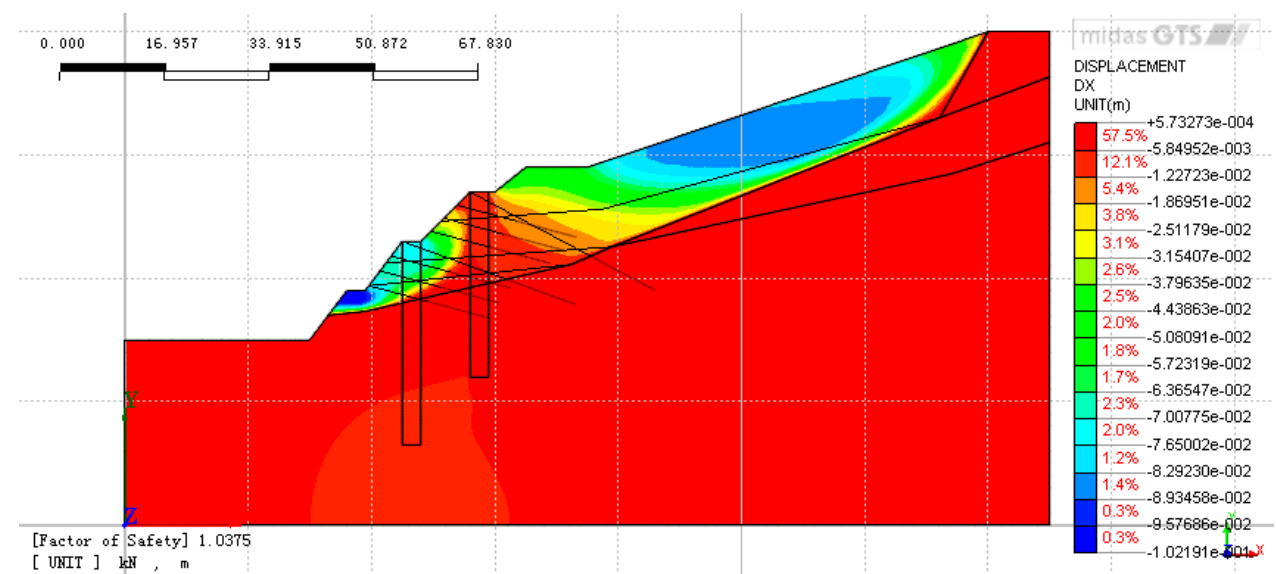

Figure 8. Horizontal displacement of the formation after initial support.

According to Figure 9 to obtain the $p$ value test results, in which the hole $9 p=0.039>0.01$; the hole $12 p=0.793>0.01$. Initially verify that the parameters selected for the simulation are valid. 


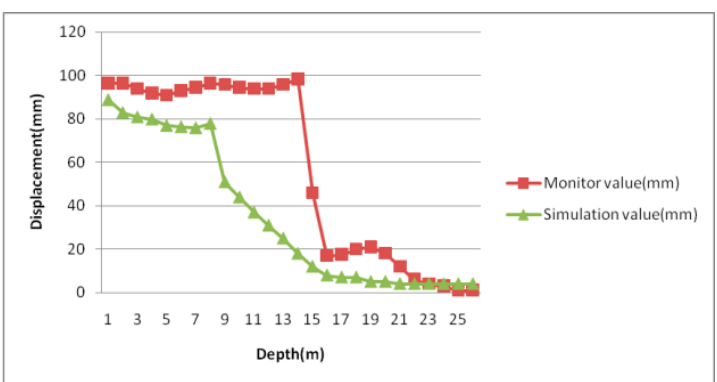

(a)

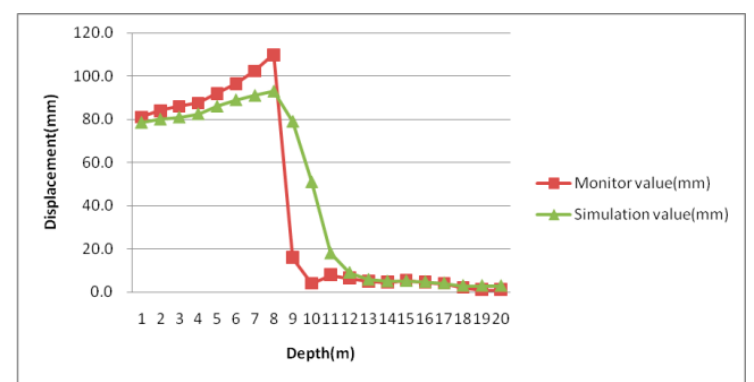

(b)

Figure 9. Horizontal displacement monitoring data and simulation data. (a) Location of hole 9 $(p=0.039) ;(b)$ Location of hole $12(p=0.793)$.

\subsection{Parameter Determination}

The parameters of the concrete and anchor cables were determined according to the definition provided by the construction code. The physical and mechanical parameters of the rock and soil layer were determined by geotechnical tests and key data self-verification methods. Tables $2-4$ list the parameters required for the calculation model.

Table 2. Rock and soil parameters.

\begin{tabular}{|c|c|c|c|c|c|c|c|}
\hline Soil Layer & $\begin{array}{c}\text { Elastic } \\
\text { Modulus } \\
\left(\mathrm{kN} / \mathrm{m}^{2}\right)\end{array}$ & $\begin{array}{l}\text { Poisson's } \\
\text { Ratio }\end{array}$ & $\begin{array}{c}\text { Angle of } \\
\text { Internal } \\
\text { Friction }\left(^{\circ}\right)\end{array}$ & $\begin{array}{l}\text { Cohesion } \\
\text { Forces } \\
\left(\mathbf{k N} / \mathbf{m}^{2}\right)\end{array}$ & $\begin{array}{c}\text { Natural Unit } \\
\text { Weight } \\
\left(\mathbf{k N} / \mathrm{m}^{3}\right)\end{array}$ & $\begin{array}{c}\text { Saturated } \\
\text { Unit Weight } \\
\left(\mathrm{kN} / \mathrm{m}^{3}\right)\end{array}$ & $\begin{array}{c}\text { Permeability } \\
\text { Coefficient } \\
\text { (m/d) }\end{array}$ \\
\hline Sliding layer & 160,000 & 0.28 & 10.5 & 12 & 18.0 & 18.5 & 0.10 \\
\hline $\begin{array}{c}\text { Gravel Soil } \\
\text { Strongly }\end{array}$ & 80,000 & 0.30 & 15.0 & 30 & 17.5 & 18.0 & 0.10 \\
\hline $\begin{array}{l}\text { Weathered } \\
\text { Mudstone }\end{array}$ & 200,000 & 0.25 & 19.0 & 50 & 19.5 & 20.0 & 0.20 \\
\hline $\begin{array}{l}\text { Moderately } \\
\text { Weathered } \\
\text { Mudstone }\end{array}$ & $1,200,000$ & 0.20 & 28.0 & 310 & 20.5 & 21.0 & 0.02 \\
\hline
\end{tabular}

Note: The sliding layer includes gravel soil layer, strongly weathered mudstone and some moderately weathered mudstone, so the elastic modulus will be higher than that of gravel soil layer. The elastic modulus and friction angle of the gravel soil layer are checked after fully considering the existing overall creep of the slope and the preliminary formation of the potential sliding surface, so they are much smaller than the experimental parameters.

Table 3. Mechanical parameters of the support structure.

\begin{tabular}{|c|c|c|c|}
\hline Structure & Elastic Modulus $\left(\mathrm{kN} / \mathrm{m}^{2}\right)$ & Unit Weight $\left(\mathrm{kN} / \mathrm{m}^{3}\right)$ & Poisson's Ratio \\
\hline Anti-Slide Pile & $2.4 \times 10^{7}$ & 25.0 & 0.3 \\
\hline Anchor & $2.0 \times 10^{7}$ & 78.5 & 0.2 \\
\hline
\end{tabular}

Table 4. Parameters of the anchor cables.

\begin{tabular}{|c|c|c|c|c|c|c|c|c|}
\hline \multicolumn{3}{|c|}{ Anchor Cable Classification } & \multirow{2}{*}{$\begin{array}{c}\begin{array}{c}\text { Slope } \\
\text { Spacing (m) }\end{array} \\
3\end{array}$} & \multirow{2}{*}{$\begin{array}{c}\text { Total Length } \\
\text { (m) }\end{array}$} & \multirow{2}{*}{$\begin{array}{c}\begin{array}{c}\text { Anchoring } \\
\text { Section (m) }\end{array} \\
10\end{array}$} & \multirow{2}{*}{$\begin{array}{c}\begin{array}{c}\text { Prestress } \\
(\mathbf{k N})\end{array} \\
500\end{array}$} & \multirow{2}{*}{$\begin{array}{c}\text { Tilt } \\
\text { Angle }\left({ }^{\circ}\right)\end{array}$} & \multirow{2}{*}{$\begin{array}{c}\begin{array}{c}\text { Aperture } \\
\text { (mm) }\end{array} \\
130\end{array}$} \\
\hline \multirow{6}{*}{$\begin{array}{c}\text { Initial } \\
\text { Support }\end{array}$} & \multirow{3}{*}{$\begin{array}{l}\text { Third } \\
\text { Slope }\end{array}$} & 1 & & & & & & \\
\hline & & 2 & 3 & 20 & 10 & 500 & 20 & 130 \\
\hline & & 3 & 3 & 20 & 10 & 500 & 20 & 130 \\
\hline & \multirow{3}{*}{$\begin{array}{l}\text { Second } \\
\text { Slope }\end{array}$} & 1 & 3 & 20 & 10 & 500 & 20 & 130 \\
\hline & & 2 & 3 & 20 & 10 & 500 & 20 & 130 \\
\hline & & 3 & 3 & 20 & 10 & 500 & 20 & 130 \\
\hline \multirow{2}{*}{\multicolumn{2}{|c|}{ Secondary Support }} & Level3 & - & 33 & 11 & 750 & 28 & 130 \\
\hline & & Level2 & - & 33 & 12 & 750 & 20 & 130 \\
\hline
\end{tabular}

Since the longitudinal spacing of anti-slide piles is $5 \mathrm{~m}$, the longitudinal width of anti-slide piles is $2.4 \mathrm{~m}$. In theory, each meter of vertical pile needs to bear the remaining sliding force of the $2.08 \mathrm{~m}$ thick 
sliding body. Therefore, it is necessary to multiply the sliding weight by 2.08 in the calculation. At the same time, in order to ensure that the original stability and safety factor does not change, the rock and soil are cohesive. The force is also multiplied by 2.08 .

\subsection{Model Results Analysis}

\subsubsection{Steady State Seepage Calculation}

From the analysis of Figure 10a-c, it can be seen that the total head of steady flow decreases from $80 \mathrm{~m}$ on the right side of the slope to $30 \mathrm{~m}$ on the left side of the slope. The pore water head and pore water pressure increase from the top of slope to the stratification down the slope; the pore water head increases from $-0.6157 \mathrm{~m}$ to $80 \mathrm{~m}$ and the pore water pressure increases from $-6.03796 \mathrm{KPa}$ to $784.532 \mathrm{KPa}$. In Figure 10d,e, the difference between the seepage velocity characteristics at different points along the slope is not obvious. However, the maximum flow rate was $1.24282 \times 10^{-6} \mathrm{~m}^{3} / \mathrm{s}$ and the minimum flow rate was $-9.46553 \times 10^{-7} \mathrm{~m}^{3} / \mathrm{s}$. The flow rate is limited by the permeability coefficient of the rock and soil layer, which impacts the difference in flow rate between points.

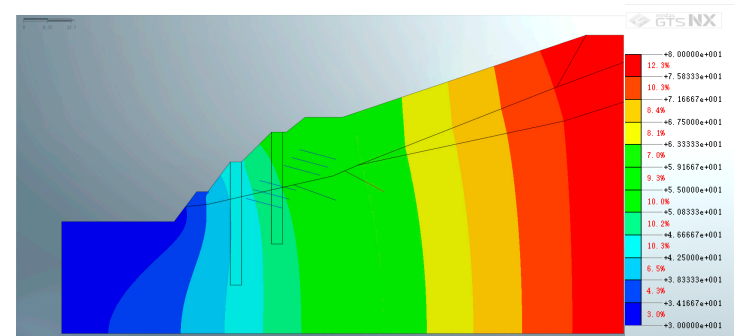

(a)

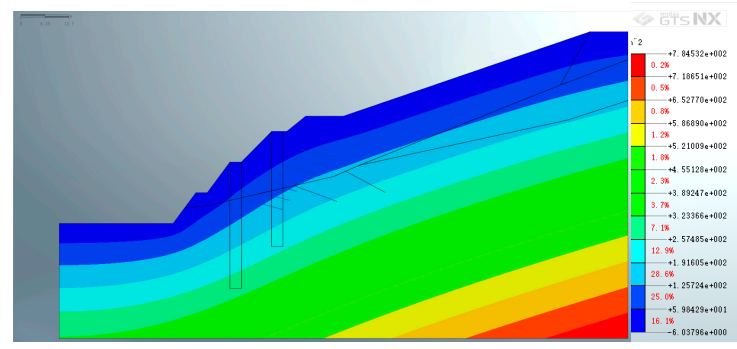

(c)

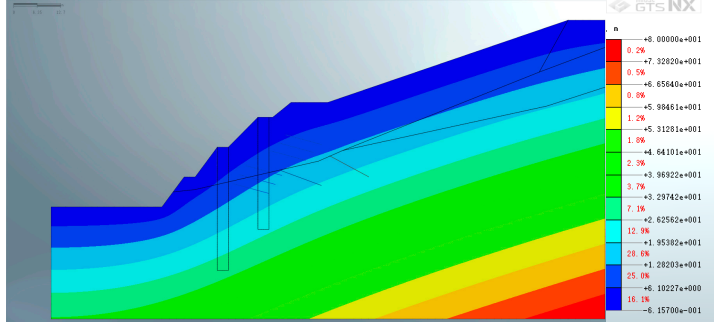

(b)

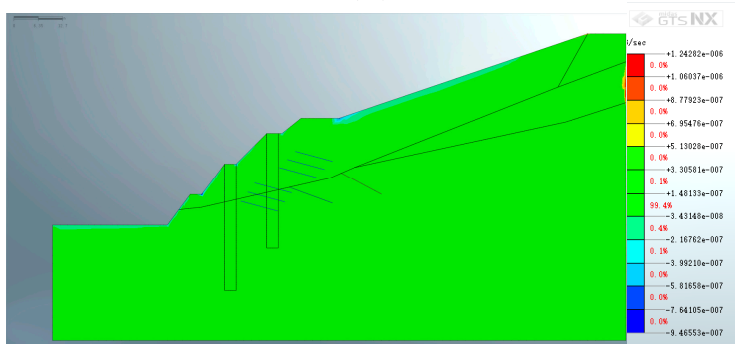

(d)

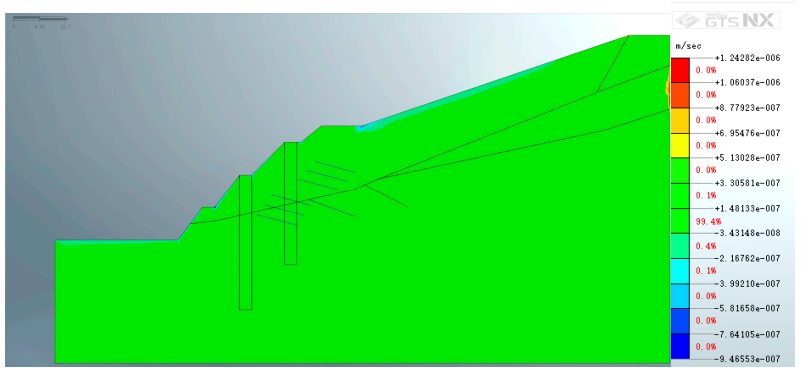

(e)

Figure 10. Seepage analysis cloud: (a) cloud map of total head height (m); (b) pore head cloud image $(\mathrm{m}) ;(\mathbf{c})$ pore water pressure cloud $(\mathrm{KPa}) ;(\mathbf{d})$ flow cloud $\left(\mathrm{m}^{3} / \mathrm{s}\right) ;(\mathbf{e})$ seepage reaction cloud $(\mathrm{m} / \mathrm{s})$.

Analysis of Figure 11a shows that the maximum hydraulic gradient of 1.86585 is located at the foot of the first-grade slope. At this location, the mechanical energy lost by the stable water flow to overcome the frictional resistance is the largest; thus, a greater driving force is required for the water flow to pass through this region. This force is superimposed on the unstable forces at the excavation position of the slope foot identified in the slope stability analysis. Thus, the hydraulic features are an unfavorable factor for slope stability. Furthermore, analysis of Figure $11 \mathrm{~b}$ shows that the combined 
maximum seepage velocity is $1.35614 \times 10^{-6} \mathrm{~m} / \mathrm{s}$, which occurs at the foot of the secondary slope and the shear exit of the potential slip surface of the surveyed slope. The speed of steady flow passing here increases and is superimposed with other unfavorable factors, such as the shear failure of the potential sliding surface of the slope, which poses a threat to the overall stability of the slope.

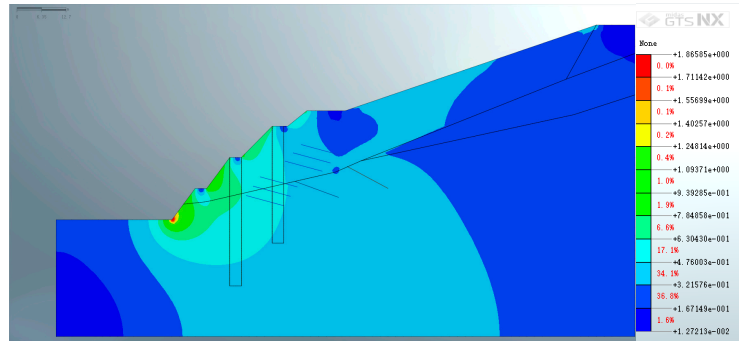

(a)

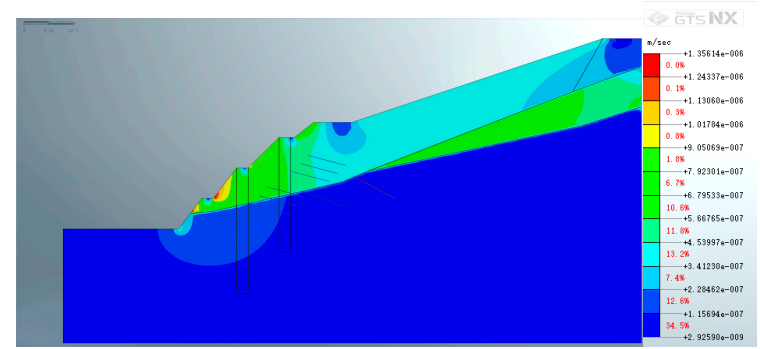

(b)

Figure 11. Seepage variable synthetic clouds. (a) Hydraulic gradient synthetic cloud(1) (b) Seepage velocity synthetic cloud $(\mathrm{m} / \mathrm{s})$.

\subsubsection{Superposition Analysis of Pore Water Pressure}

The joint pore water pressure determined from the seepage analysis was added to the slope excavation, primary support, and secondary support stage simulations. Subsequently, the stress-strain characteristics of the slope and the changing safety factor was investigated.

Figures 12-14 depict the slope characteristics following the completion of the excavation stage. Analysis of Figure 12 shows that the maximum displacement of the slope after excavation is slightly reduced after applying pore water pressure $(6.39322 \mathrm{~cm}$ without considering pore water pressure compared to $6.35777 \mathrm{~cm}$ with pore water pressure applied). The reason for the decrease in the extreme value of the total displacement is the complex pressure (including but not limited to the excess pore water pressure) of the pore water pressure in the gravel soil (high permeability). At the same time, the comparative analysis results of Figures 13 and 14 show that the equivalent strain of the slope and the XY stress have a decreasing trend. After the application of pore water pressure, the maximum displacement zone below the excavation position of the slope is absent, though it is present when pore water pressure is not applied. Furthermore, after the pore water pressure is applied, the maximum displacement of the slope is concentrated at the top of the slope, and the displacement of the slope gradually decreases from the top to the foot of the slope.

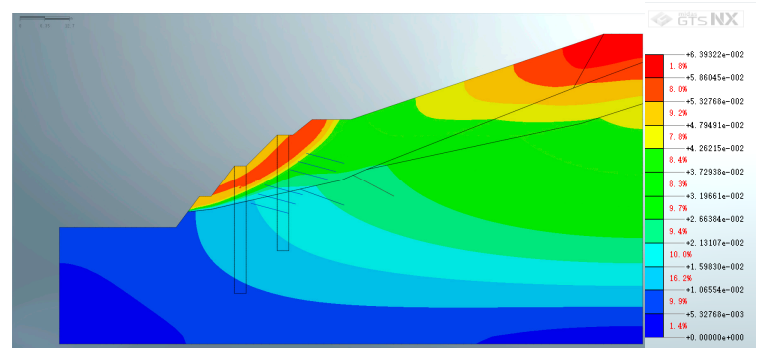

(a)

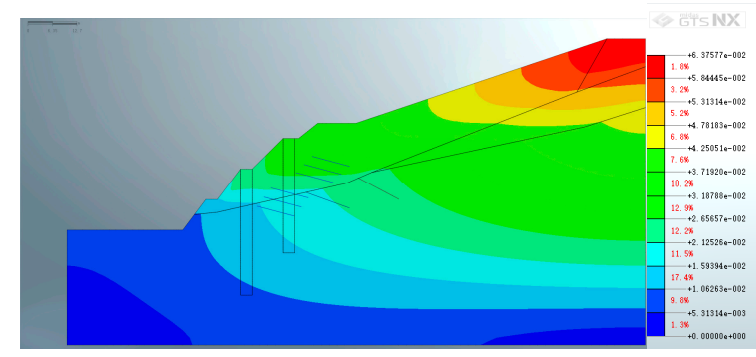

(b)

Figure 12. Total slope displacement (a) without pore water pressure applied (m) (b) with pore water pressure applied (m). 


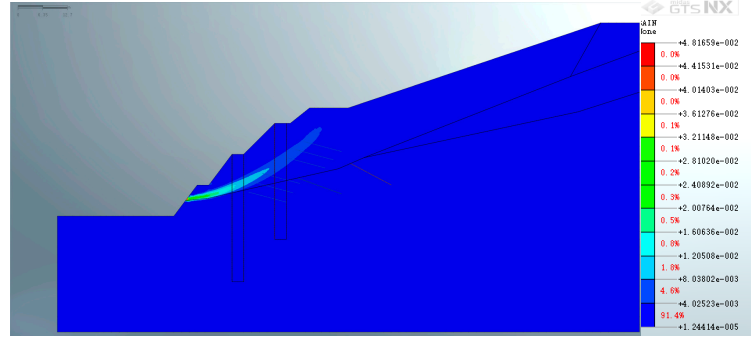

(a)

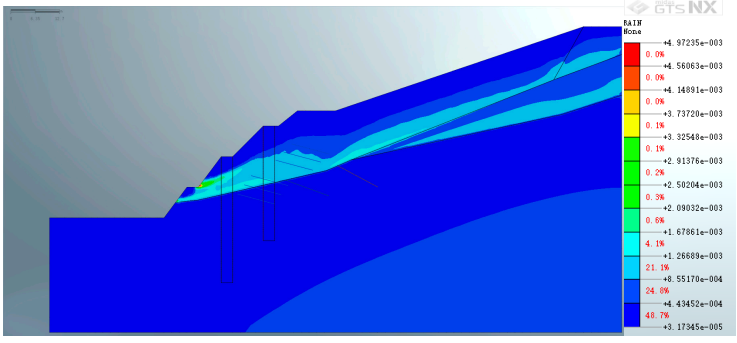

(b)

Figure 13. Slope equivalent strain (a) without pore water pressure applied (1) (b) with pore water pressure applied (1).

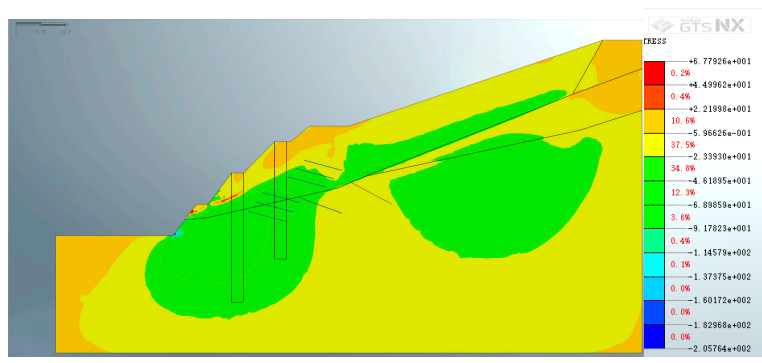

(a)

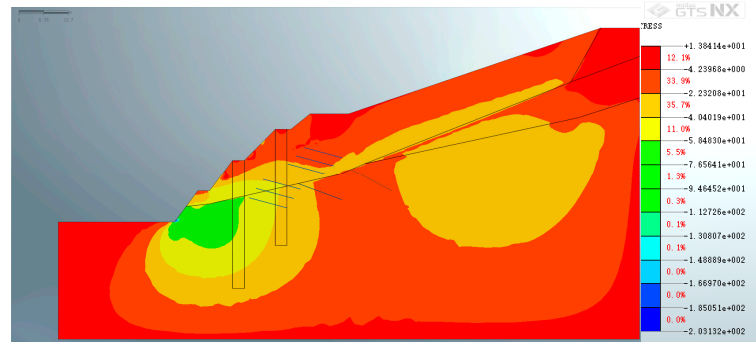

(b)

Figure 14. $\mathrm{XY}$ stress (a) without pore water pressure applied $(\mathrm{KPa})(\mathbf{b})$ with pore water pressure applied $(\mathrm{KPa})$.

Figure 13 shows the changes in the equivalent strain distribution after excavation when pore water pressure is considered. The maximum value of the equivalent strain is reduced from $4.81659 \times 10^{-2}$ without pore water pressure to $4.97235 \times 10^{-3}$ with pore water pressure. Furthermore, the equivalent strain distribution pattern changes from the circular arc distribution under the excavated slope (without pore water pressure) to the potential slip surface at the interface between the rock and soil layers (with pore water pressure). Thus, Figure 13b shows that steady-state seepage in the dual structure slope is likely to lead to the formation of a new continuous sliding zone along the potential slip surface, threatening the overall stability of the slope. Importantly, the new equivalent strain distribution state is more consistent with the theory that rainwater seepage can reduce the shear strength of the potential slip surface of the slope.

Analysis of the stress concentration along the slope before and after applying pore water pressure shows that the site of stress concentration is consistently at the foot of the first grade of the slope (Figure 14). After the application of pore water pressure, the maximum stress value was very slightly reduced from $-2.05764 \times 10^{2} \mathrm{kPa}$ to $-2.03132 \times 10^{2} \mathrm{kPa}$. More significantly, after applying pore water pressure, the band zone of stress distribution below the original first and second slopes disappears. In addition, the safety factor of the slope was reduced from 0.625 to 0.6 after applying pore water pressure. This shows that the seepage effect has an adverse effect on the stability of the dual-structure slope, but this influence is limited when the flow is steady.

Figures 15-17 depict the slope characteristics following the construction of the first support structure. Figure 15 shows that the application of pore water pressure has a greater influence on the total displacement of the slope after the initial support is constructed. The continuous total displacement distribution zone on the slope above the original anti-slide pile is mitigated by the pore water pressure being considered. The maximum displacement of the slope is always at the shear outlet of the potential slip surface determined from the survey, and the extreme value of the displacement 
increases from $0.723785 \mathrm{~m}$ to $2.58239 \mathrm{~m}$. In this condition, the first and second slopes could easily collapse. Thus, further protective measures are required.

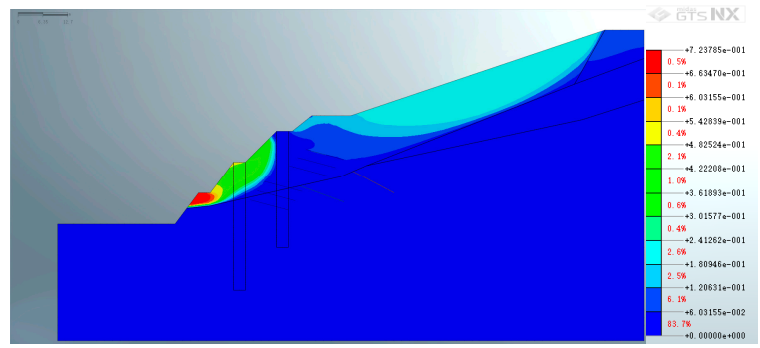

(a)

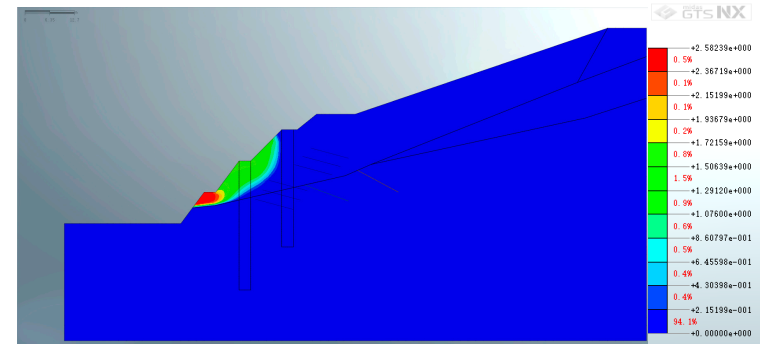

(b)

Figure 15. Total slope displacement (a) without pore water pressure applied (m) (b) with pore water pressure applied (m).

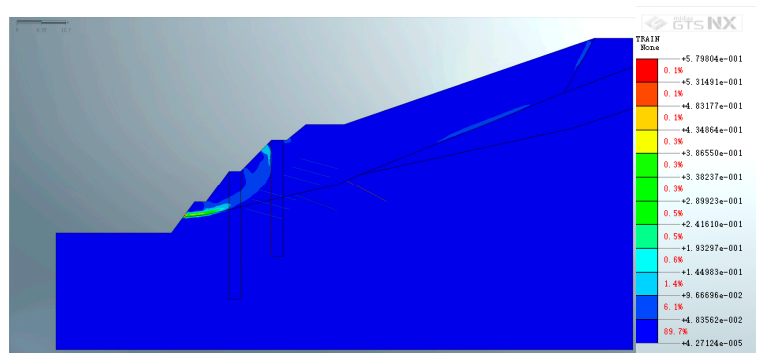

(a)

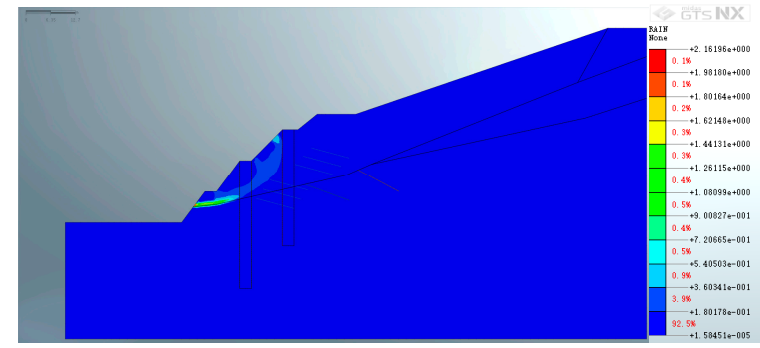

(b)

Figure 16. Slope equivalent strain (a) without pore water pressure applied (1) (b) with pore water pressure applied (1).

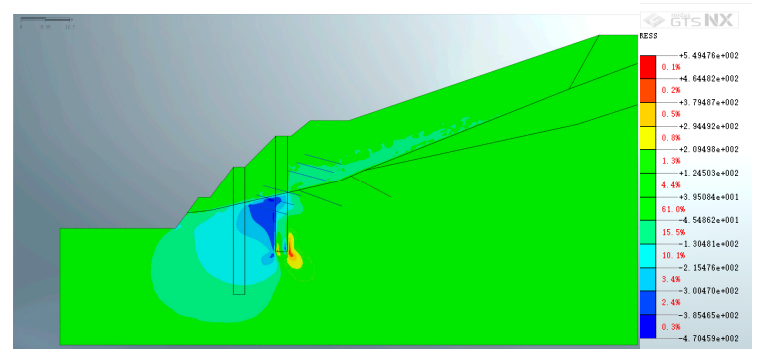

(a)

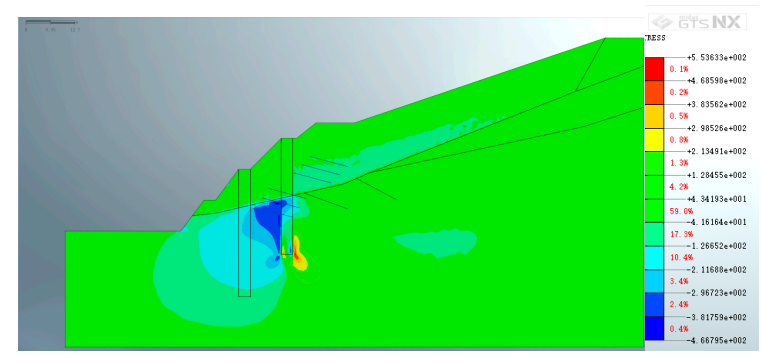

(b)

Figure 17. $X Y$ stress (a) without pore water pressure applied $(\mathrm{KPa})(\mathbf{b})$ with pore water pressure applied (KPa).

Figure 16 shows that the application of pore water pressure has little effect on the position of the equivalent strain distribution along the slope. However, the application of pore water pressure led to an order of magnitude increase in the maximum equivalent strain, which increased from 0.579804 (without pore water pressure) to 2.16196 (with pore water pressure). This shows that steady-state seepage has a significant influence on the ultimate strain of the slope, which causes the shear strength of the slope rock and soil to be challenged.

Figure 17 shows that the application of pore water pressure has little effect on the location of the maximum stress distribution after the first slope support is constructed. The stress is distributed near the front and back of the bottom end of the anti-slide pile in both cases, and the addition of pore water pressure increased the absolute value of the maximum stress only marginally from $5.49476 \times 10^{2} \mathrm{kPa}$ 
to $5.53633 \times 10^{2} \mathrm{kPa}$. In addition, the safety factor of the slope decreased from 1.0219 to 1.0188 after applying the pore water pressure of steady flow. This suggests that steady-state seepage has an adverse effect on slope stability, but the impact is limited.

After the initial support, due to the reinforcement of anti-slide piles and anchor cables, the slope strain and deformation extremes are further concentrated towards the toe of the slope. As a result, the toe of the slope is in an under-stable state, which affects the overall stability of the slope. Considering the accumulation of adverse effects of seepage action on strain and displacement, secondary support measures should be applied.

Figures 18-20 depict the characteristics of the slope after the construction of the second support structure. Figure 18 shows that the application of pore water pressure has little effect on the location of the maximum displacement distribution after the secondary support is constructed on the dual-structure slope. However, it has a great influence on the size and position of the extreme value. After applying pore water pressure, the maximum displacement above the excavated slope decreased from $8.27889 \times 10^{-1} \mathrm{~m}$ to $2.28734 \times 10^{-1} \mathrm{~m}$. Furthermore, the displacement of the shear outlet position of the potential slip plane decreased slightly from $4.82935 \times 10^{-1} \mathrm{~m}$ to $2.74481 \times 10^{-1} \mathrm{~m}$ after pore water pressure was applied.

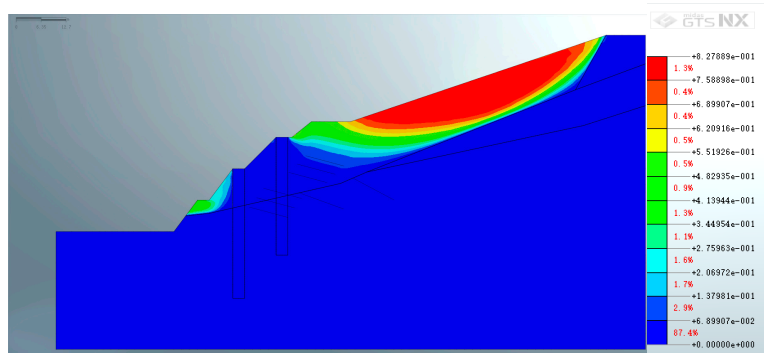

(a)

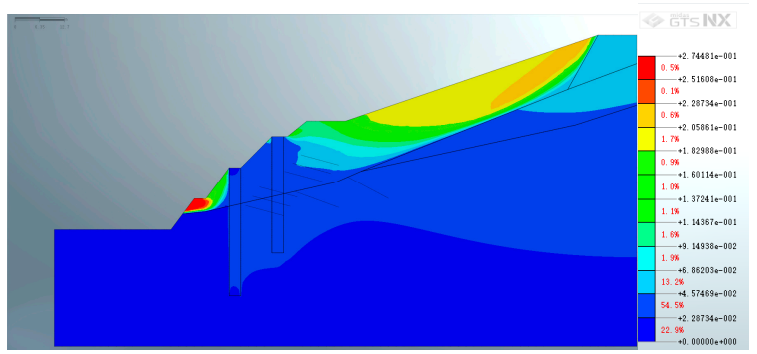

(b)

Figure 18. Total slope displacement (a) without pore water pressure applied $(\mathrm{m})(\mathbf{b})$ with pore water pressure applied (m).

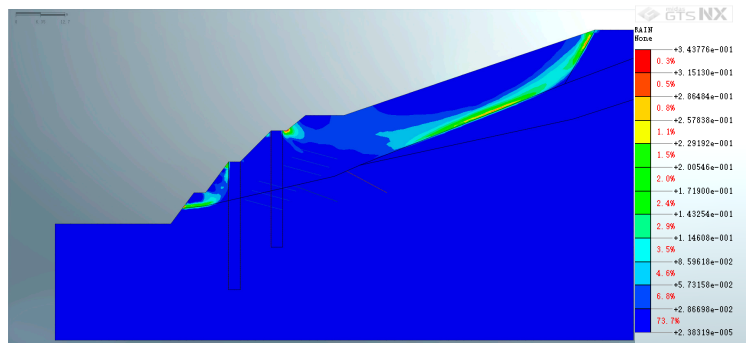

(a)

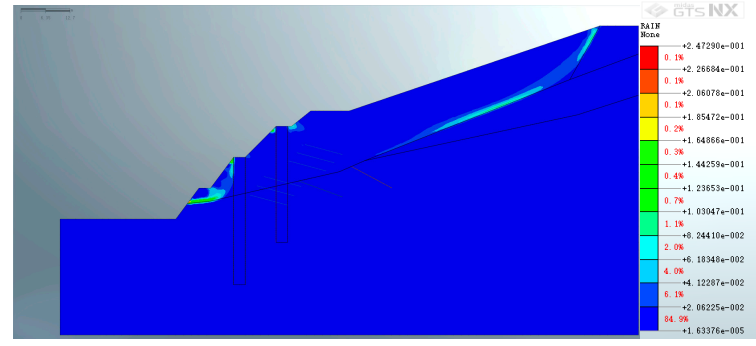

(b)

Figure 19. Slope equivalent strain (a) without pore water pressure applied (1) (b) with pore water pressure applied (1).

Figure 19 shows that the application of pore water pressure has an effect on the equivalent strain extreme value and distribution position of the binary structure slope. The distribution of equivalent strain extremums is reduced from three locations on the potential slip surface-above the slope the top of the anti-slide pile in the first construction and the shear outlet of the potential slip surface-to one location on the potential slip surface after the application of pore water pressure. The maximum equivalent strain extreme value is reduced from $3.43776 \times 10^{-1}$ to $2.4729 \times 10^{-1}$ after pore water pressure application. In short, the maximum equivalent strain and distribution along the potential slip surface above the slope are reduced. Thus, the application of pore water pressure has a positive effect on the stability of the binary structure above the slope after the second support is constructed. 


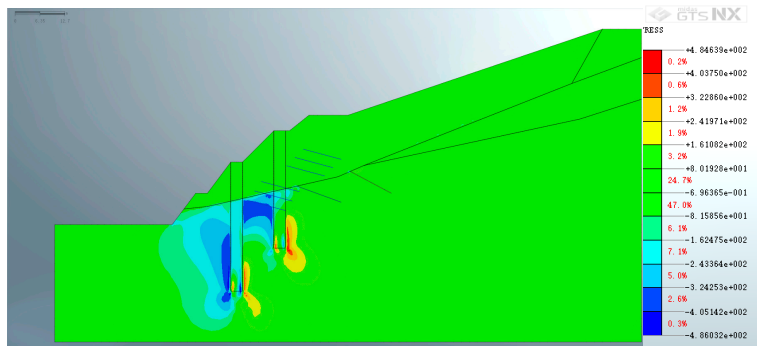

(a)

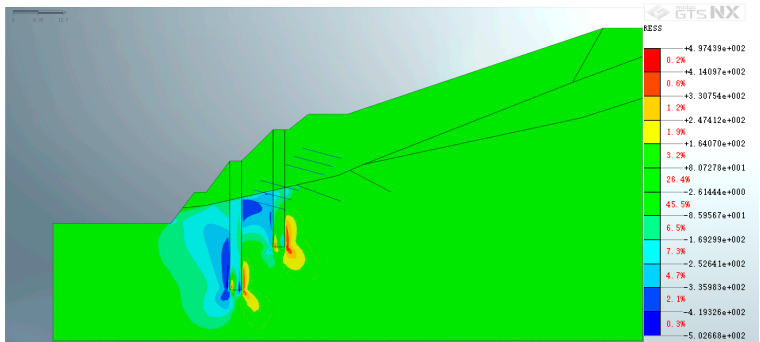

(b)

Figure 20. $X Y$ stress (a) without pore water pressure applied $(\mathrm{KPa})(\mathbf{b})$ with pore water pressure applied $(\mathrm{KPa})$.

Figure 20 shows that the application of pore water pressure has little effect on the distribution of $X Y$ stress concentration after secondary support construction. The absolute value of maximum stress increased slightly from $4.86032 \times 10^{2} \mathrm{kPa}$ to $5.02668 \times 10^{2} \mathrm{kPa}$. The stress concentration extends along the front and back of the bottom of the anti-slide pile in a butterfly-shaped distribution that spreads away from the pile. In addition, the application of pore water pressure reduced the safety factor of the dual-structure slope from 1.0754 to 1.025. As for the other stages, steady-state seepage thus has an adverse effect on slope stability, but the impact is limited.

\section{Discussion}

The seepage analysis of the dual structure mainly focuses on monitoring statistics or status analysis, lacking verification of the parameters used, and no corresponding process analysis. The existing slope seepage analysis and calculation are mainly controlled by geotechnical parameters. The determination of parameters has been a contentious issue in this field. The current methods are: (1) obtained through geotechnical tests; (2) based on statistical data obtained from a large number of similar strata; (3) empirical data. Because the parameters obtained by the geotechnical test are different from the actual project, they need to be revised. The method of statistical data is only applicable to ordinary strata and requires a lot of engineering accumulation. The empirical data are convenient to use, but obviously lack scientificity. In addition, the existing three parameter acquisition methods have fatal disadvantages for slopes in special geological environments: the parameter selection method is not universal, and the universality and sustainability are poor. In order to solve these problems, this paper uses deep displacement monitoring data and $p$ value test to verify the simulation parameters, and puts forward an analysis method of the dual slope excavation and support process.

Seepage stability analysis of dual structure slopes to date has mainly focused on separate calculation or state analysis. This type of analysis lacks the superposition calculation method and corresponding process analysis. In this study, deep displacement monitoring data was used to verify simulation parameters and the superposition calculation method for steady-state seepage and slope geotechnical structure analysis was implemented. The strength reduction method was used to superimpose the pore water pressure distribution on the examined dual-structure slope during excavation and support construction. A comparative analysis of the displacement, strain, stress, and safety factor of the slope at each stage was performed after the application of pore water pressure. These results are valuable to the evaluation of dual-structure slope stability in the rainy season.

The total displacement, equivalent strain, and XY stress extreme values at the completion stage of slope excavation are shown in Table 5, combined with Figures 12-14 to obtain the following conclusion: After the completion of slope excavation, the application of pore water pressure has a limited effect on the maximum slope displacement and causes the maximum displacement distribution along the slope below the excavation site to disappear. This shows that steady-state seepage has a significant effect on the distribution and magnitude of slope displacement and that monitoring and construction along a dual-structure slope is complex during the rainy season. Furthermore, the equivalent strain 
distribution of the slope changes with pore water pressure application from the arc-shaped distribution under the excavated slope to the potential slip surface and rock-soil layer interface. Thus, steady-state seepage can easily lead to the formation of a new continuous sliding zone along the potential sliding surface, reducing the overall stability of the slope. However, the application of pore water pressure has a limited effect on the location and magnitude of the stress concentration distribution and the slope safety factor. Thus, in summary, the impact of steady-state seepage on the slope following excavation is mainly reflected in the total displacement and equivalent strain measures. Practically, this indicates that the analysis of stress concentration and safety factors is therefore insufficient to meet the safety requirements for construction and monitoring during the rainy season.

Table 5. Extreme value of each operating condition.

\begin{tabular}{|c|c|c|c|c|c|}
\hline $\begin{array}{l}\text { Operated } \\
\text { Condition }\end{array}$ & $\begin{array}{l}\text { Pore Water } \\
\text { Pressure }\end{array}$ & $\begin{array}{c}\text { Displacement } \\
\text { (m) }\end{array}$ & $\begin{array}{l}\text { Equivalent } \\
\text { Strain (1) }\end{array}$ & Stress (Kpa) & Safety Factor \\
\hline \multirow{2}{*}{$\begin{array}{l}\text { Excavation } \\
\text { completed }\end{array}$} & No & $\begin{array}{l}6.39322 \times 10^{-1} \\
\text { (Slope top) }\end{array}$ & $4.81659 \times 10^{-2}$ & $\begin{array}{c}-2.05764 \times 10^{2} \\
\text { (Slope foot) }\end{array}$ & 0.6125 \\
\hline & Yes & $\begin{array}{l}6.37577 \times 10^{-1} \\
\quad \text { Slope top) }\end{array}$ & $4.97235 \times 10^{-3}$ & $\begin{array}{c}-2.03132 \times 10^{2} \\
\text { (Slope foot) }\end{array}$ & 0.6000 \\
\hline \multirow[t]{2}{*}{ First support } & No & $\begin{array}{c}7.23785 \times 10^{-1} \\
(\text { Slope foot) }\end{array}$ & $5.79804 \times 10^{-1}$ & $\begin{array}{l}5.49476 \times 10^{2} \\
\quad(\text { Pile end) }\end{array}$ & 1.0219 \\
\hline & Yes & $\begin{array}{c}2.58239 \\
\text { (Slope foot) }\end{array}$ & $2.16196 \times 10^{-1}$ & $\begin{array}{l}5.53633 \times 10^{2} \\
\quad \text { (Pile end) }\end{array}$ & 1.0188 \\
\hline \multirow[t]{2}{*}{ Second support } & No & $\begin{array}{c}4.82935 \times 10^{-1} \\
(\text { Slope foot) }\end{array}$ & $3.43776 \times 10^{-1}$ & $\begin{array}{l}4.86032 \times 10^{2} \\
(\text { Pile end })\end{array}$ & 1.0754 \\
\hline & Yes & $\begin{array}{l}2.74481 \times 10^{-1} \\
(\text { Slope foot })\end{array}$ & $2.47290 \times 10^{-1}$ & $\begin{array}{l}5.02668 \times 10^{2} \\
(\text { Pile end })\end{array}$ & 1.0250 \\
\hline
\end{tabular}

The total displacement, equivalent strain and $X Y$ stress extreme values of the slope at the completion stage of the initial support are shown in Table 5, combined with Figures 15-17 to obtain the following conclusion: After the construction of the first slope support, pore water pressure has an obvious effect on the total displacement of the slope, as the distribution of slope displacement above the anti-slide pile disappears when pore water pressure is applied. In this case, the maximum displacement of the slope is concentrated at the shear outlet of the potential slip surface and the maximum displacement increases by $257 \%$, providing additional evidence that a secondary support measure is essential. At this stage, pore water pressure has little effect on the position of the equivalent strain distribution, but does have an amplifying effect on the magnitude of the equivalent strain. This shows that steady-state seepage has a significant adverse effect on the ultimate strain of the dual-structure slope after reinforcement, and demonstrates that this indicator needs to be monitored during reinforcement construction. The application of pore water pressure has little effect on the location or magnitude of the stress concentration at this stage and has only a limited negative impact on the safety factor of the slope. In summary, the impact of steady-state seepage in after the initial support construction stage is mainly reflected in the total displacement and equivalent strain. Practically, these indicators should be analyzed during construction and monitoring to avoid stress concentration and adverse impacts on safety.

Finally, the total displacement, equivalent strain, and $X Y$ stress extreme values of the slope secondary support at the completion stage are shown in Table 5, combined with Figures 18-20, we can get: After the construction of the second support structure, the application of pore water pressure exerts a significant influence on the maximum displacement of the slope. Specifically, pore water pressure application reduces the maximum displacement by up to $72.4 \%$ and reduces the displacement at the exit position of the potential slip plane up to $43.2 \%$. Pore water pressure has little effect on the range of the displacement distribution along the slope. Thus, the positive effect of steady-state seepage on slope displacement was demonstrated at this stage. This stage affects the slope equivalent strain distribution range and extreme value: the number of equivalent strain extremes along the slope 
was reduced from three to one and the maximum equivalent strain decreased by $28.1 \%$. Therefore, the distribution position and size of stress concentration were less affected. Additionally, the application of pore water pressure slightly reduced the safety factor of the slope. In summary, the indices of the effects of steady-state seepage on slope stability following secondary support construction are the total displacement and the equivalent strain. Uniquely, at this stage, pore water pressure has a positive impact on these two indicators. Thus, careful attention should be paid to pore water pressure during the slope support construction and monitoring phases.

\section{Conclusions}

The sustainability research and scientific development of seepage analysis of slope engineering faces three bottlenecks: (1) The choice of simulation parameters is fuzzy. (2) The process analysis is difficult. (3) The application of pore water pressure. This study examined the right-side slope management project of the $\mathrm{K} 5+220$ to $\mathrm{K} 5+770$ section of the TJ1A mark of the Jiangkou-Weng'an Highway in Guizhou province. For the verification of the simulation parameters, actual deep displacement monitoring and $p$ value test were used. The strength reduction method was then used to superimpose steady-state seepage flow on the slope during the excavation of the dual-structure slope and the two-stage construction of support structures for the slope. The effect of the applied pore water pressure on the deformation characteristics of the slope was examined in depth. A comparative analysis of the displacement, strain, stress, and safety factor characteristics of the slope was performed after the application of pore water pressure was considered for each of the three stages. The conclusions of this study are as follows:

1. Demonstrate the use of deep displacement monitoring data and $p$ value to verify the simulation parameters verified. A superposition calculation method for analysis of steady-state seepage and slope geotechnical structures is proposed. The impact analysis of node pore water pressure during excavation and support construction was performed successfully.

2. A novel process analysis methods is proposed and applied. The strength reduction method was used to superimpose the pore water pressure on the analysis of the excavation and support construction for the dual-structure slope. Integrated stability analyses were then performed for each of the three slope stages.

3. It is found that steady-state seepage has a significant effect on the displacement of the slope during excavation; Steady seepage can form a continuous strain distribution zone at the interface between the sliding layer and the bedrock. This can then form a continuous sliding zone, which reduces the overall stability of the slope. Steady-state seepage had a limited effect on the stress concentration at this stage but slightly reduces the safety factor as determined by the strength reduction method.

4. It is found that steady-state seepage has a significant effect on the position of the displacement distribution and the extreme value of the displacement of the shear outlet during the initial support construction for the slope. At this stage, the extreme value of equivalent strain increased greatly when pore water pressure was considered. The displacement and strain analysis showed the necessity of secondary support measures and suggested that displacement and strain analysis during construction and monitoring should be considered. Steady-state seepage had little effect on the stress concentration, but slightly reduced the stability factor of the slope, as determined by the strength reduction method.

5. It is found that steady-state seepage reduced the displacement and the maximum equivalent strain after the secondary support of the slope were constructed. In particular, steady-state seepage had a positive effect on the equivalent strain distribution for the slope at this stage. Similar to the other stages, seepage had little effect on the stress concentration but slightly reduced the safety factor of the slope as determined by the strength reduction method.

The superposition calculation method used in this paper is a popular method for slope seepage calculation, which can be easily extended to other commercial or self-programmed software. Thus, 
the method described in this work is expected to establish a bridge between on-site monitoring, seepage field and slope rock and soil studies. With regards to future work, the analysis method for slope stability processes proposed in this paper needs further study, and further research on the stress analysis of slope support structures is needed.

Author Contributions: X.G.; conceptualization, methodology, software, validation, data analysis, investigation, resources, data curation, writing - original-draft preparation, review and editing, data visualization, and project supervision. B.C.; conceptualization, validation, and funding acquisition. W.T.; conceptualization, validation, and funding acquisition. Z.Z.; validation and project administration. J.L.; conceptualization and validation. H.Q.; data analysis and investigation. All authors have read and agreed to the published version of the manuscript.

Funding: This work was funded by the Western Transportation Construction Science and Technology Project [2006-318-000-07], the CCCC (China Communications Construction Co., Ltd.) Technology Research and Development Project (2011-ZJKJ-01), the National Natural Science Foundation of China [51708043], the Fundamental Research Funds for the Central Universities, CHD [300102219106] and the Fundamental Research Funds for the Central Universities, CHD [300102219209].

Conflicts of Interest: The authors declare no conflict of interest.

\section{References}

1. Zheng, Y.R.; Chen, Z.Y.; Wang, G.X.; Ling, T.Q. Engineering Treatment of Slope \& Landslide, 2nd ed.; People's Communication Press: Beijing, China, 2010.

2. Editorial Board of Engineering Geology Manual. Handbook of Engineering Geology, 4th ed.; China Construction Industry Press: Beijing, China, 2007.

3. Zang, K.; Men, F. The basic law of seepage in porous media. Earthq. Eng. Eng. Vib. 1990, 10, 75-82.

4. Terzaghi, K. Theoretical Soil Mechanics; John Wiley \& Sons, Inc.: New York, NY, USA, 1943.

5. Terzaghi, K.; Peek, R.B. Soil Mechanics in Engineering Practice; John Wiley \& Sons, Inc.: New York, NY, USA, 1948.

6. Shao, L.; Li, H. Geotechnical Structure Stability Analysis-Finite Element Limit Equilibrium Method and Its Application; Science Press: Beijing, China, 2011.

7. Mao, C.; Chen, P.; Li, Z.; Li, D.F. Finite element analysis of dam slope stability under seepage. Chin. J. Geotech. Eng. 1982, 4, 87-106.

8. Liu, J. Soil Seepage Stability and Seepage Control; China Water Resources Press: Beijing, China, 1992.

9. Lam, L.; Fredlund, D.G.; Barbour, S.L. Transient seepage model for saturated unsaturated soil systems: A geotechnical engineering approach. Can. Geotech. J. 1987, 24, 565-580. [CrossRef]

10. Shao, L. Skeletal stress equation of saturated soil. Chin. J. Geotech. Eng. 2011, 33, 1833-1837.

11. Mao, C.; Li, J.; Duan, X. Finite element calculation of circular arc sliding of soil slope under seepage. Chin. J. Geotech. Eng. 2001, 23, 746-752.

12. Gao, X.; Liao, H.; Ding, C. The effect of seepage on the stability of soil slope. Rock Soil Mech. 2004, 25, 69-72.

13. Zhang, G. Research on the Influence of Water Level Change on Landslide Stability; China University of Geosciences: Beijing, China, 2005.

14. Zhang, W.; Zhan, L.; Ling, D.S.; Chen, Y.M. Effect of water level fluctuation on the stability of unsaturated soil bank slope in reservoir area. J. Zhejiang Univ. (Eng. Sci. Ed.) 2006, 40, 1365-1370.

15. Wang, X.; Zhang, Y.; Zou, W.; Xing, C.F. Numerical simulation of unsaturated embankment deformation and slope stability under rainfall infiltration conditions. Rock Soil Mech. 2010, 31, 3640-3644.

16. Zhang, Z.; Gao, X. Analysis method and application of loess slope stability based on Midas/GTS. J. Water Resour. Arch. Eng. 2016, 4, 182-185.

17. Calista, M.; Pasculli, A.; Sciarra, N. Reconstruction of the geotechnical model considering random parameters distributions. Eng. Geol. Soc. Territ. 2015, 2, 1347-1351. [CrossRef]

18. Liu, W.; Luo, X.; Huang, F.; Fu, M. Uncertainty of the Soil-Water Characteristic Curve and Its Effects on Slope Seepage and Stability Analysis under Conditions of Rainfall Using the Markov Chain Monte Carlo Method. Water 2017, 9, 758. [CrossRef] 
19. Pasculli, A.; Calista, M.; Sciarra, N. Variability of local stress states resulting from the application of Monte Carlo and finite difference methods to the stability study of a selected slope. Eng. Geol. 2018, 245, 370-389. [CrossRef]

20. Liu, Y. Hydraulics; China Water Resources Press: Beijing, China, 2008.

(C) 2020 by the authors. Licensee MDPI, Basel, Switzerland. This article is an open access article distributed under the terms and conditions of the Creative Commons Attribution (CC BY) license (http://creativecommons.org/licenses/by/4.0/). 